\title{
EDITORIAL
}

\section{SCAT in the Wilderness}

\author{
Karen M. Johnston, MD, PhD, FRCSC, FACS \\ Wilderness Medical Society member; Chair of Concussion in Sport Group-International Ice Hockey Federation, Federation Internationale \\ de Football, and International Olympic Committee Medical Commission; Neurosurgeon/Concussion Consultant, Departments of \\ Neurosurgery, Kinesiology, and Physical Education, McGill University, and Director of Concussion Program, McGill Sport Medicine Centre, \\ Montreal, Quebec, Canada.
}

Bob Norris is correct, some surfing is an indoor sport ${ }^{1}$ and a pretty low risk for trauma, except maybe for carpal tunnel overuse injuries! However, in that same recent issue of our journal ${ }^{2}$ we also open to page 75 to have illustrated for us a perfect example of two main issues in sport concussion. First, and no surprise to Wilderness Medical Society practitioners or participants, we learn that head injuries certainly do occur in the sport medicine "subspecialty" of wilderness medicine in, but not limited to, activities such as surfing, ${ }^{2-5}$ glacial sports, ${ }^{6,7}$ off-road biking, ${ }^{8,9}$ high-altitude events, ${ }^{10}$ hiking, rafting, swimming, and back-country activities, ${ }^{11}$ to name a few. Second, this article highlights thinking that mirrors the main driving force for the recent International Concussion meeting held in Prague in November 2004. That is, athletes and health care providers do not necessarily know when a concussion is sustained and an important component of protection and education is included in the most-effective management.

Two goals that were achieved were unprecedented before the First International Concussion Symposium in Vienna in 2001, brought together by the Federation Internationale de Football, the International Olympic Committee Medical Commission, and the International Ice Hockey Federation. Consensus by experts on concussion topics was developed for the first time, culminating in the development of the Concussion in Sport Group, and the document from that meeting was simultaneously published in 3 separate journals (copyright to the authors! - the point being that dissemination of the material free of charge would improve the health care of the concussed athlete). ${ }^{12-14}$ The success of that endeavor was acclaimed to the extent that, 3 years later, the update meeting in Prague, in November, 2004, was a monumental success. The resulting papers were published recently, again in multiple journals, ${ }^{15-18}$ and are available

\footnotetext{
Corresponding author: Dr Karen M. Johnston, McGill Sport Medicine Clinic, 475 Pine Ave West, Montreal, Quebec, Canada, H2W 1S4, (e-mail: kmjohnston@sympatico.ca).
}

for download from websites of the publishing journals and other nonprofit injury-prevention groups, such as www.thinkfirst.ca, all free of charge. The publication reviews and updates the current definition of concussion; the classification-introducing the simple vs complex concussion injury; outlines important clinical issues, including the preparticipation exam, signs and symptoms, cognitive testing, management strategies, rehabilitation and return to play approaches, and research issues. In addition, the new SCAT (Sport Concussion Assessment Tool, named as a token effort to remind us that we are still in the wilderness), is a standardized tool for assessment and patient education, and is also downloadable from www.wemjournal.org.

Thus, although postinjury extrication may vary whether you are sacked as a quarterback or fall off your llama, the principles of management of the concussion are identical. I encourage interest in this user-friendly downloadable document and tool and persuade you that it was not only inspired by professional or Olympic sport but by the many recreational sporting activities that potentially could get any of us injured, in back or front country, at altitude or depth.

\section{Acknowledgments}

The Summary and Agreement Statement of the 2nd International Conference on Concussion in Sport, Prague $2004^{18}$ and the Sport Concussion Assessment Tool (SCAT) are reprinted at www.wemjournal.org with permission. Copyright (C) 2005 by the Concussion in Sport Group.

\section{References}

1. Norris R. Surfing is an indoor sport. Wilderness Environ Med. 2005;16(2):61.

2. Taylor DM, Bennett D, Carter M, Garewal D, Finch C. Perceptions of surfboard riders regarding the need for pro- 
tective headgear. Wilderness Environ Med. 2005;16(2):7580 .

3. Nathanson A, Haynes P, Galanis D. Surfing injuries. Am J Emerg Med. 2002;20(3):155-60.

4. Sunshine S. Surfing injuries. Curr Sports Med Rep. 2003; 2(3):136-141.

5. Taylor DM, Bennett D, Carter M, Garewal D, Finch CF. Acute injury and chronic disability resulting from surfboard riding. J Sci Med Sport. 2004;7(4):429-437.

6. Johnson SM, Johnson AC, Barton RG. Avalanche trauma and closed head injury: adding insult to injury. Wilderness Environ Med. 2001;12(4):244-247.

7. Schindera ST, Triller J, Steinbach LS, Zimmermann H, Takala J, Anderson SE. Spectrum of injuries from glacial sports. Wilderness Environ Med. 2005;16(1):33-37.

8. Chow TK, Kronisch RL. Mechanisms of injury in competitive off-road bicycling. Wilderness Environ Med. 2002;13(1):27-30.

9. Kronisch RL, Pfeiffer RP. Mountain biking injuries: an update. Sports Med. 2002;32(8):523-537.

10. Thole RT. Preparation and medical management of events in mountain and high-altitude environments. Curr Sports Med Rep. 2004;3(3):128-133.

11. Newman LM, Diekema DS, Shubkin CD, Klein EJ, Quan L. Pediatric wilderness recreational deaths in western Washington State. Ann Emerg Med. 1998;32(6):687-692.

12. Aubry M, Cantu R, Dvorak J, et al. Summary and agreement statement of the First International Conference on
Concussion in Sport, Vienna 2001. Recommendations for the improvement of safety and health of athletes who may suffer concussive injuries. Br J Sports Med. 2002;36(1): 6-10.

13. Aubry M, Cantu R, Dvorak J, et al. Summary and agreement statement of the 1st International Symposium on Concussion in Sport, Vienna 2001. Phys Sportsmed. 2002; 30(2):57-63.

14. Aubry M, Cantu R, Dvorak J, et al. Summary and agreement statement of the 1st International Symposium on Concussion in Sport, Vienna 2001. Clin J Sport Med. 2002;12(1):6-11.

15. McCrory P, Johnston K, Meeuwisse W, et al. Summary and agreement statement of the 2nd International Conference on Concussion in Sport, Prague 2004. Br J Sports Med. 2005;39(4):196-204.

16. McCrory P, Johnston K, Meeuwisse W, et al. Summary and agreement statement of the 2nd International Conference on Concussion in Sport, Prague 2004. Physician \& Sports Medicine. 2005;33(4):29-44.

17. McCrory P, Johnston K, Meeuwisse W, et al. Summary and agreement statement of the 2nd International Conference on Concussion in Sport, Prague 2004. Neurosurgery. In press.

18. McCrory P, Johnston K, Meeuwisse W, et al. Summary and agreement statement of the 2nd International Conference on Concussion in Sport, Prague 2004. Clin J Sport Med. 2005;15(2):48-55. 